Article

\title{
Temporary Fault Ride-Through Method in Power Distribution Systems with Distributed Generations Based on PCS
}

\author{
Jung-Hun Lee ${ }^{1}\left(\mathbb{D}\right.$, Seung-Gyu Jeon ${ }^{1}$, Dong-Kyu Kim ${ }^{1}$, Joon-Seok $\mathrm{Oh}^{2}$ and Jae-Eon Kim ${ }^{1, * \mathbb{D}}$ \\ 1 School of Electric Engineering, Chungbuk National University, Cheongju 28644, Korea; \\ leejh6800@naver.com (J.-H.L.); sgjeon@cbnu.ac.kr (S.-G.J.); kimdk8079@naver.com (D.-K.K.) \\ 2 Department of Distribution Planning, Korea Electric Power Corporation (KEPCO), Naju 58322, Korea; \\ simeter@naver.com \\ * Correspondence: jekim@cbnu.ac.kr; Tel.: +82-10-9028-2423
}

Received: 30 December 2019; Accepted: 27 February 2020; Published: 2 March 2020

check for updates

\begin{abstract}
The current practice of Distributed Generation (DG) disconnection for every fault in distribution systems has an adverse effect on utility and stable power trading when the penetration level of DGs is high. That is, in the process of fault detecting and Circuit Breaker (CB) reclosing when a temporary fault occurs, DGs should be disconnected from the Point of Common Coupling (PCC) before $\mathrm{CB}$ reclosing. Then all DGs should wait at least 5 minutes after restoration for reconnection and cannot supply the pre-bid power in power market during that period. To solve this problem, this paper proposes a control method that can keep operating without disconnection of DG. This control method is verified through modeling and simulation by the PSCAD/EMTDC software package for distribution systems with DGs based on PCS (Power Conditioning Systems) and CB reclosing protection.
\end{abstract}

Keywords: fault restoration; distribution generation; temporary fault ride-through; voltage control; inrush current control

\section{Introduction}

At present, the exhaustion of resources and environmental problems are continuously intensifying due to the indiscriminate use of fossil fuels. As a result, the Paris Convention, which will replace the Kyoto Protocol, which is scheduled to expire in 2020, was adopted at the Paris Climate Change Conference in France in 2015 with a focus on converting renewable energy sources into alternative energy sources for fossil fuels worldwide. Accordingly, the deployment of Distributed Generation (DG) based on Power Conditioning Systems (PCS) such as photovoltaic generation and wind power generation are rapidly increasing worldwide [1,2].

In this way, PCS-based DG without inertia may have some negative effects on reliability and power quality in power systems if it is introduced on a large scale. In particular, when a temporary fault occurs in distribution systems with many PCS-based DGs, they should be disconnected from the Point of Common Coupling (PCC) before Circuit Breaker (CB) reclosing. Then the voltage becomes unstable. Moreover, all DGs interconnected to distribution systems should wait more than 5 minutes for reconnection after restoration and cannot supply the pre-bid power in power market during that period $[3,4]$. In such a case, power trading cannot be performed, thereby leading to not only economic damages, but also unstable system operation such as power quality, etc. [5,6].

In this regard, the only existing studies for rapid restoration from faults are as follows: a multi-stage/multiple micro-grid technique for dividing the islanding operation section [7,8], an islanding operation method engaging the droop control of the DG when the fault section is isolated [9-13], a voltage control strategy that involves switching between the grid-connected mode and islanding 
operation mode for the VSC (Voltage-Sourced Converters) type of DGs [14], a Multi Agent System (MAS) technique for dividing switches, DGs, and load into agents for quick fault restoration [15-20], and a fault restoration method for minimizing the number of switch operations for load transfer [21]. However, these papers have focused on permanent faults and temporary faults have not been considered. That is, there are no measures against the voltage problems caused by the opening of CBs or recloser upon fault occurrence, disconnection of all DGs, and temporary inrush current problems caused by their reclosing.

On the other hand, in the conventional FRT(Fault Ride Through) regulations for grid code, when a fault occurs in transmission systems, the time required for fault detection and isolation is around $150 \mathrm{~ms}$ to $160 \mathrm{~ms}$, and after that it takes about $2 \mathrm{~s}$ to return to the steady-state voltage. Taking this into consideration, DG should continue to operate within this range [22-26]. Control methods for complying with FRT operating conditions in which DG keeps operating during an accident are currently proposed and applied $[27,28]$. However, when a temporary fault occurs in distribution systems, CB operates within 5-6 cycles (about $0.1 \mathrm{~s}$ ) immediately after a temporary fault occurs and then returns to the steady-state operation by performing CB reclosing within $0.5 \mathrm{~s}$. As this abnormal condition is severe compared with the fault situation in transmission systems, FRT for temporary faults in distribution systems could not be considered until now and there were no suggestions to solve it. In addition, there is a problem with determining whether the fault is temporary or permanent before CB reclosing.

Therefore, in this paper, a temporary fault ride-through method in distribution systems is proposed. Section 2 describes the method of restoration from a fault in conventional distribution systems, and Section 3 describes some problems during restoration processes. Section 4 proposes a control method where all DGs connected to distribution systems can continue to operate even if a temporary fault occurs. In Section 5, the proposed method is verified through simulation by PSCAD/EMTDC and analysis.

\section{Conventional Restoration Method for Temporary Faults}

In distribution systems, the reclosing operation of a $\mathrm{CB}$ or $\mathrm{RC}$ (Recloser) is applied in order to determine whether there has been a fault, temporary or permanent [29-31]. The general protection method in distribution systems is described below.

The protection devices to break fault current in distribution systems are composed of a CB at the substation outlet and reclosers on distribution lines, which can detect a fault and reclose. In the following the characteristic operation of a CB and recloser is described.

\section{1. $C B$}

The operation of a CB at the substation outlet is carried out and ensured with some relays like Over Current Relay (OCR), Over Current Ground Relay (OCGR), and reclosing relay. There are various types of setting methods depending on the configuration of distribution lines. Basically, the $C B$ acts as back-up protection for recloser downstream on distribution lines and reclosing operation to decide whether a fault is temporary or permanent. Then the CB retains lock-out and open state for a permanent fault.

\subsection{Recloser}

Recloser is generally installed on distribution lines and detects a fault, breaks the fault's current, and automatically performs the reclosing operation within a specified time. Reclosing is also applied because more than $80 \%$ of faults are temporary faults that are eliminated by themselves in a temporary period [32].

If the fault persists, the last reclosing function should be performed, followed by lock-out and open state. When a fault occurs on distribution lines, the upstream recloser nearest the fault point should perform the reclosing operation in accordance with specified operation obligation and satisfy the main or back-up protection relationship with CB at upstream substation. Figure 1 shows an operation 
example of the recloser under the occurrence of a fault between RC1 and RC2-RC1 is opened to break the fault current supplied from substation.

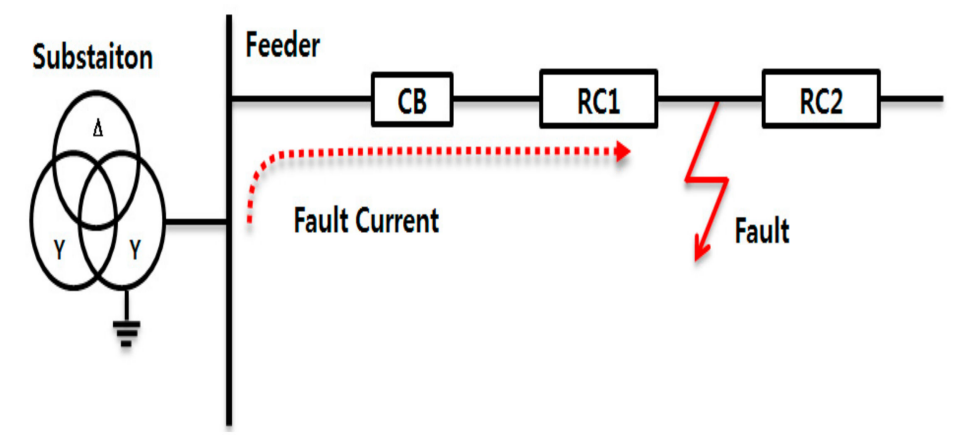

Figure 1. Configuration of the Circuit Breaker (CB) and Recloser (RC) in distribution systems.

The operating characteristics of a recloser generally operate with Two-Fast Two-Delay (2F2D). This can be accomplished by two fast trips and two delayed trips in order to eliminate fault or determine permanent lock-out. Figure 2 illustrates the 2F2D reclosing processes.

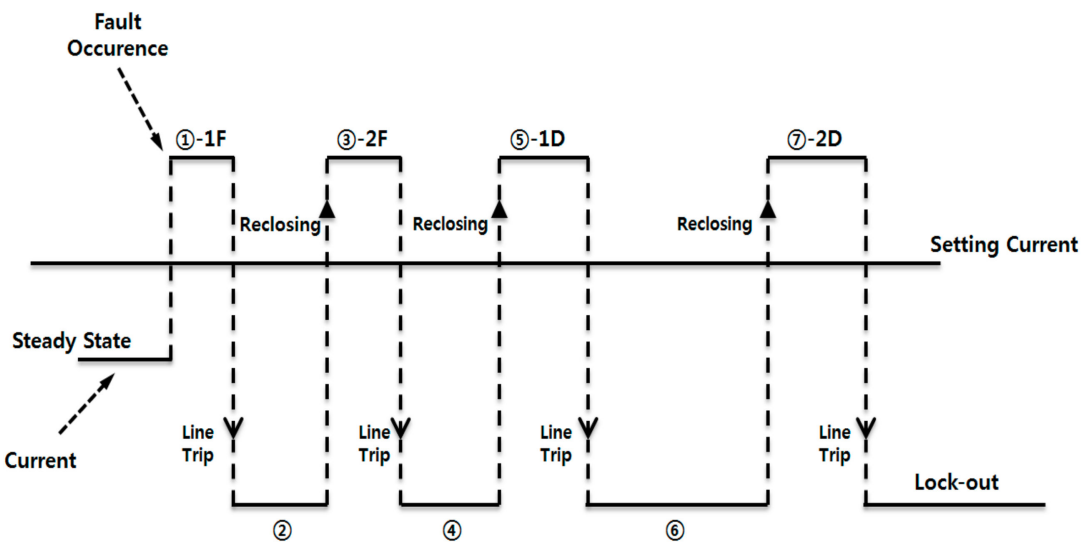

Figure 2. Typical Two-Fast Two-Delay (2F2D) operating scheme example of recloser.

\section{Critical Problems in Conventional Fault Restoration Method}

\subsection{Discontinuity of DG Supply by Anti-Islanding Function}

One of critical problems in the conventional fault restoration method is that the CB or recloser is opened when a fault occurs, and all DGs and loads on the stream line of the CB or recloser are islanding. At this time, for the safety of the human body and the protection of over-voltage due to the ratio of the power generation to the load, all DGs should detect the islanding state and be disconnected. In addition, after the fault is eliminated, distribution systems will be restored, and they will be reconnected after 5 minutes for normal operation based on grid code [32]. Then, DG cannot supply the pre-bid power to power market.

\subsection{Power Quality Problems during Islanding Operation}

When a fault occurs in distribution systems, the CB and recloser on distribution lines operate as shown in Figure 3. In order to prevent the islanding operation of the DG due to the opening of this recloser, there are several national grid codes as seen in Table 1. Most grid codes require that the islanding state should be detected and DG disconnected within around $0.5-2 \mathrm{~s}$, considering the reclosing operation of a CB or recloser. This means that islanding operation may occur for $0.5-2 \mathrm{~s}$ after detecting a fault, which may cause power quality problems such as frequency and voltage fluctuation beyond permissible ranges and result in equipment damage and human body danger. As shown in 
Figure 3, when the output of aggregated DGs is larger than aggregated loads in the islanding region, the over-voltage phenomenon occurs in a just few milliseconds after islanding operation, which may adversely affect loads, equipment, and the human body. In addition, in the case of an under-voltage, even if the fault is eliminated, a situation in which DG is disconnected occurs.

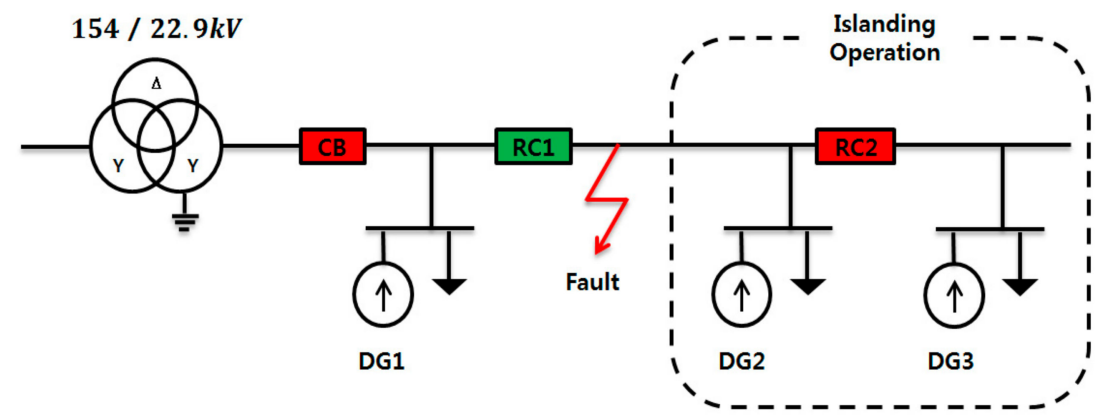

Figure 3. Configuration of AC grid with distributed generators. DG: Distributed Generation.

Table 1. Anti-islanding requirements in grid codes.

\begin{tabular}{ccc}
\hline Name & Requirements & Detection Method \\
\hline IEEE 1547 \\
IEC 61727 [22,33] & Cease to energize within 2 s of the formation of the island & Active or Passive \\
\hline $\begin{array}{c}\text { VDE-AR-N 4105 } \\
\text { [34] }\end{array}$ & Disconnect in $5 \mathrm{~s}$ & Active or Passive \\
\hline BDEW 2008 & Network operator may have special requirements & Not specified \\
[35] & Detect within 0.5-1.0 s & Active \\
JEAC 9701-2012 & Detect within 0.5 s & Passive \\
\cline { 2 - 3 } KEPCO Guideline & Cease to energize within 0.5 s of the formation of the island & Active or Passive \\
\hline 3$]$
\end{tabular}

IEEE: Institute of Electrical and Electronics Engineers, IEC: International Electrotechnical Commission, VDE: Verband Der Elektrotechnik, BDEW: Bundesverband der Energie-und Wasserwirtschaft, JEAC: Japan Electric Association Code, KEPCO: Korea Electric Power Corporation.

The ratio of DG output to load in the islanding region has the largest influence on voltage problems. This is an important factor, because the voltage $V_{i s}$ during islanding is determined by the ratio as follows [37]:

$$
V_{i s}=\frac{\text { Total amount of power generation }}{\text { Total amount of load demand }}
$$

The load characteristic can be classified into three types: constant power, constant current, and constant impedance. Generally, power systems have all three types of load. The voltage $V_{i s}$ of the islanding condition can be expressed as shown in Equation (2) when DG with constant power is connected to a load with constant impedance $[38,39]$.

$$
V_{i s}=V_{L} \frac{\sqrt{\sqrt{P_{D G}^{2}+Q_{D G}^{2}}}}{\sqrt{\sqrt{P_{L}^{2}+Q_{L}^{2}}}}
$$

$V_{\text {is }} \quad$ Voltage amplitude during islanding.

$V_{L} \quad$ Voltage amplitude under steady-state.

$P_{D G} \quad$ Output active power of DG.

$Q_{D G}$ Output reactive power of DG. 
$P_{L} \quad$ Active power of load.

$Q_{L} \quad$ Reactive power of load.

Equation (2) means that the voltage during islanding is proportional to the square root of the apparent power ratio of DG to load. The research to solve this problem is currently underway on the output control of DG when islanding operation occurs. Several papers have applied the output control through the droop control of DG [11-15]. However, these controls have a slow response to prevent over-voltage, which rises rapidly due to the output control by the droop characteristic curve. Therefore, this paper considers that the voltage magnitude is controlled to be 0.5 p.u., which is the permissible voltage operation range of VRT (Voltage Ride Through), for the voltage problem during islanding operation generated by Equation (2).

\section{Temporary Fault Ride-Through Method}

Temporary fault most commonly occurs in distribution systems, and is eliminated before the first reclosing of the recloser. However, due to recloser opening, the anti-islanding function of DG is triggered, and all DGs are disconnected. Therefore, this paper proposes a control method to prevent unnecessary disconnection of DG in the case of a temporary fault. This method is defined as the Temporary Fault Ride-Through (TFRT), and consists of two controllers-Low/High Voltage Ride Through (L/HVRT) and Inrush Current Suppressing controller. The former suppresses over/under-voltages during temporary fault and the latter inrush current due to voltage amplitude and phase difference between both sides of a $\mathrm{CB}$ or recloser at their reclosing time. This control is described below.

\subsection{L/HVRT Controller}

The L/HVRT Controller controls the voltage to keep it within a permissible VRT range in an overor under-voltage situation, which may occur by the ratio of generation to load after recloser opening. If a temporary fault occurs while operating with active and reactive power reference $\left(P_{\text {reference, }}, Q_{\text {reference }}\right)$ in steady-state, the recloser is open and the fault condition, which is unbalanced voltage, is maintained and after the temporary fault is eliminated, it changes to islanding operation state under balanced voltage. At this time, as shown in Figure $4 a$, the output reference d-axis current value of the controller is controlled through the PI (Proportional-Integral) controller so that the PCC voltage remains within VRT range. In this paper, the rms voltage $V_{R M S}$ at the PCC is considered to be controlled to maintain

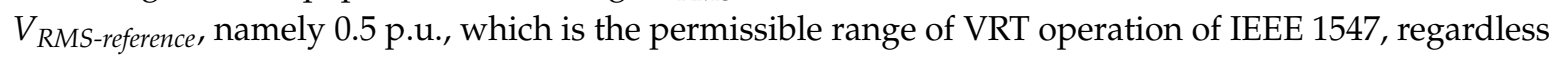
of the ratio of generation to load. At this time, as shown in Figure $4 \mathrm{~b}$, active power output is controlled by the q-axis current value $I_{q_{-} \text {control }}$, which is the square root of the square of the d-axis current value $I_{d_{-} \text {control }}$ subtracted from the square of the rated maximum current $I_{M}$ of DG to be controlled within the rated range of the DG output. 


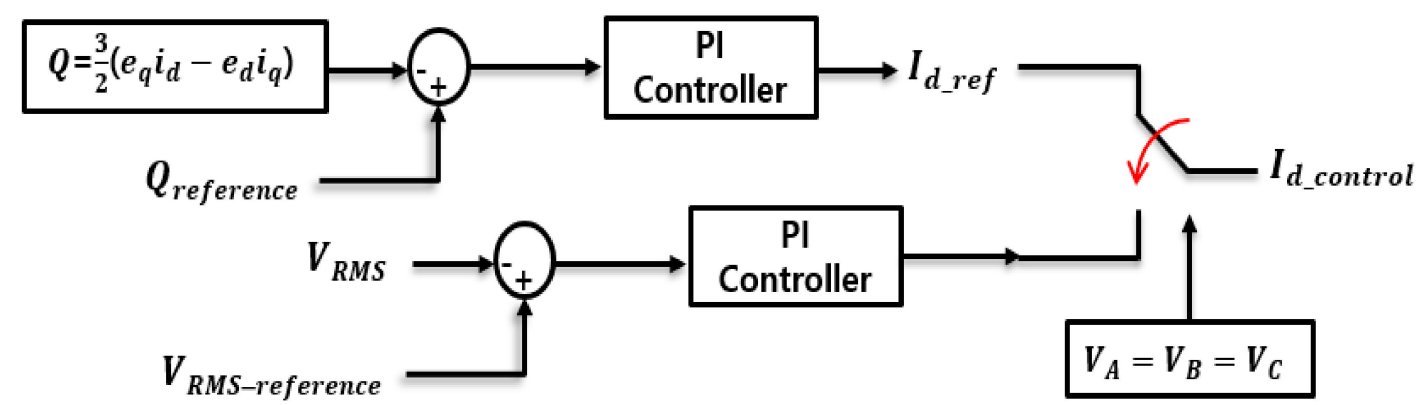

(a)

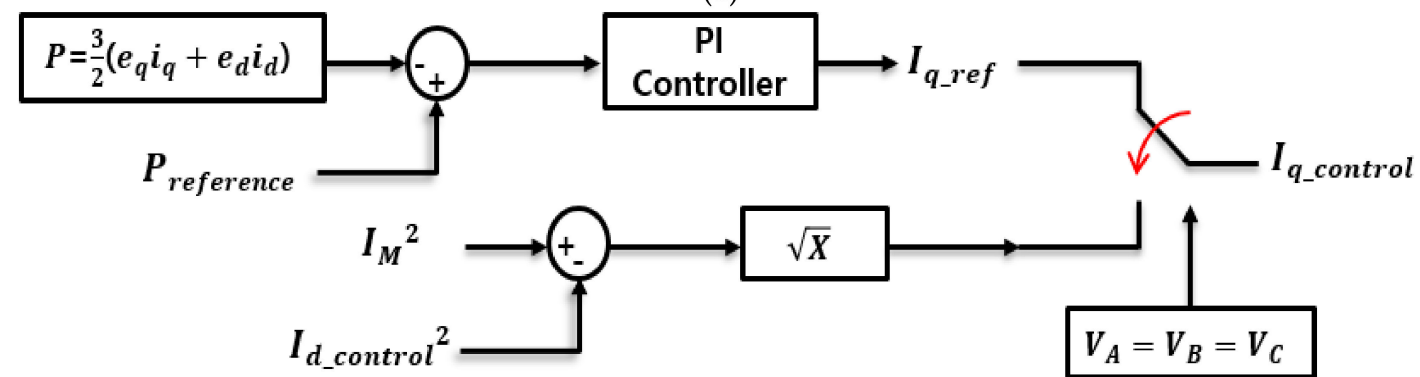

(b)

Figure 4. Block diagram of Low/High Voltage Ride Through (L/HVRT) controller. (a) $I_{d}$ Current Controller; (b) $I_{q}$ Current Controller.

\subsection{Inrush Current Suppressing Controller}

When the $\mathrm{CB}$ or recloser recloses, inrush current occurs due to the magnitude and phase difference of voltage between both their terminals. Since the inrush current has a negative effect on the PCS equipment and feeders, a control method of suppressing the inrush current is necessary. The magnitude of the inrush current $I_{\text {inrush }}$ is derived as Equation (3) in the equivalent circuit of Figure 5, which is fed into DG and load. At this time, at the PCC of DG, the derivative value of current $I_{\text {derivative_max }}$ flowing into DG is measured and multiplied to voltage reference $V_{d, q_{-} r e f e r e n c e}$ to be controlled as shown in Figure 6. Then the output current $I_{D G}$ from DG is shown in the blue line and offsets the inrush current $I_{\text {inrush }}$ shown in the red line in Figure 5. This control is implemented during a few cycles just after reclosing.

$$
I_{\text {inrush }}=\frac{V_{S} \angle 0-V_{R} \angle \theta}{R+j X}
$$

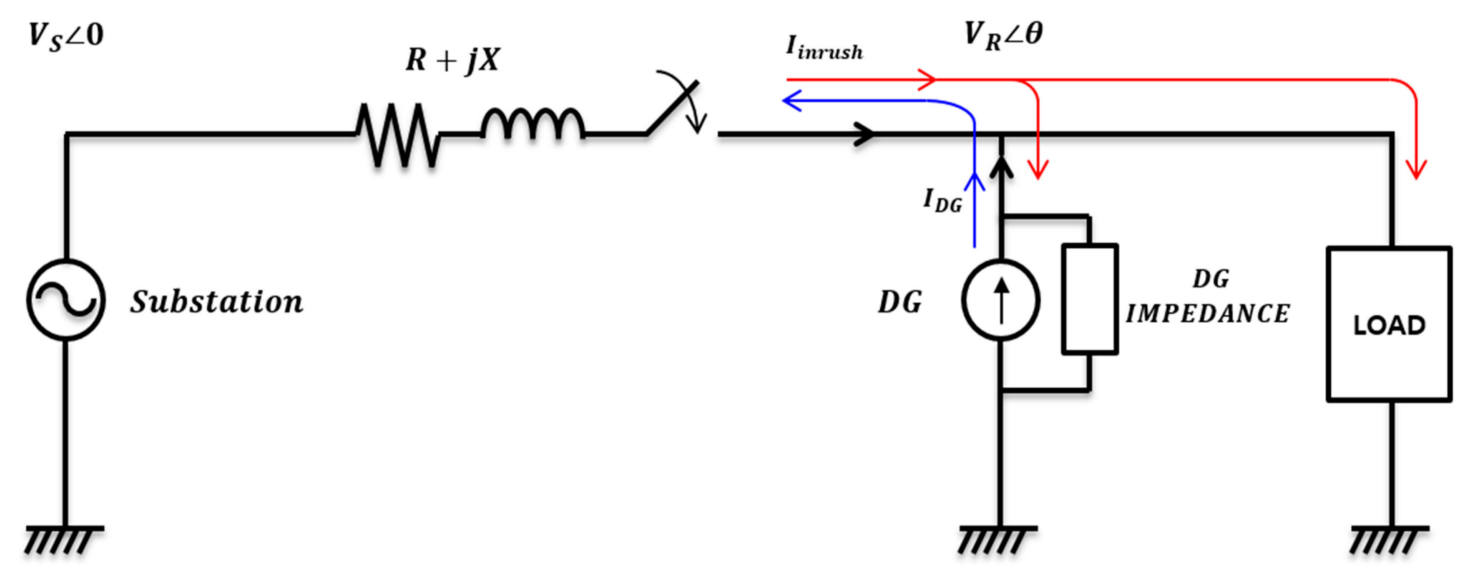

Figure 5. Equivalent circuit of current flowing in distribution systems with DG and loads. 


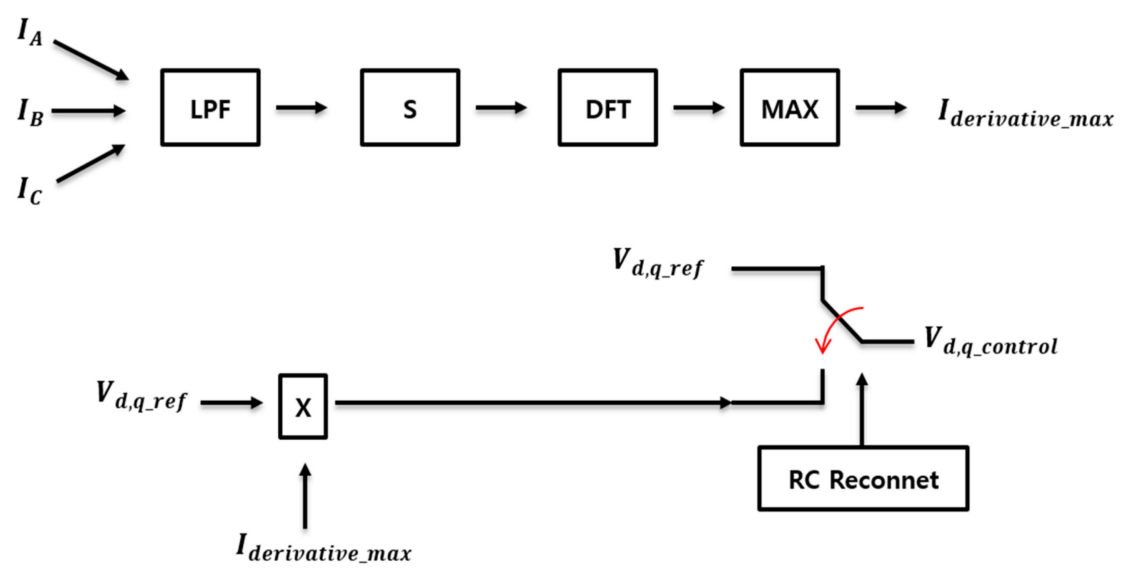

Figure 6. Block diagram of inrush current suppressing controller. LPF: Low Pass Filer, S; Differentiator, DFT: Discrete Fourier Transform.

$I_{\text {inrush }}$ Current amplitude when recloser reclosing.

$I_{D G} \quad$ Current amplitude of DG.

$V_{S} \quad$ Voltage amplitude of substation.

$V_{R} \quad$ Voltage amplitude of DG.

$\theta \quad$ Phase difference of substation and DG.

\subsection{TFRT Algorithm}

The FRT in the conventional grid code allows DG to continue operation without disconnection in the event of a fault in transmission systems, but under this condition, it cannot be applied in the event of a temporary fault in distribution systems. This is because the fault conditions of transmission systems and distribution systems are different, as described in the introduction. Therefore, this paper proposes a Temporary Fault Ride-Through (TFRT) algorithm so that DG can continue to operate in the temporary fault condition. The TFRT algorithm using the controller described in Sections 4.1 and 4.2 is shown in Figure 7. If a fault is detected on a feeder, the CB or recloser opens with their first fast operation, and then DG will run in islanding operation. If the unbalanced voltage continues until the reclosing operation of the $\mathrm{CB}$ or recloser, $\mathrm{DG}$ perceives the fault as permanent fault and is disconnected from the PCC. If the voltage is balanced, DG perceives the fault as a temporary fault and conducts control to maintain the voltage within a permissible operating range of the VRT. Here, the reference voltage value $V_{R M S}$ was determined as 0.5 p.u., considering the VRT operating range of IEEE 1547. When the fault is eliminated and the $\mathrm{CB}$ or recloser is reclosed, the proposed controller suppresses inrush current to minimize severe or critical damages to DG and distribution systems. 


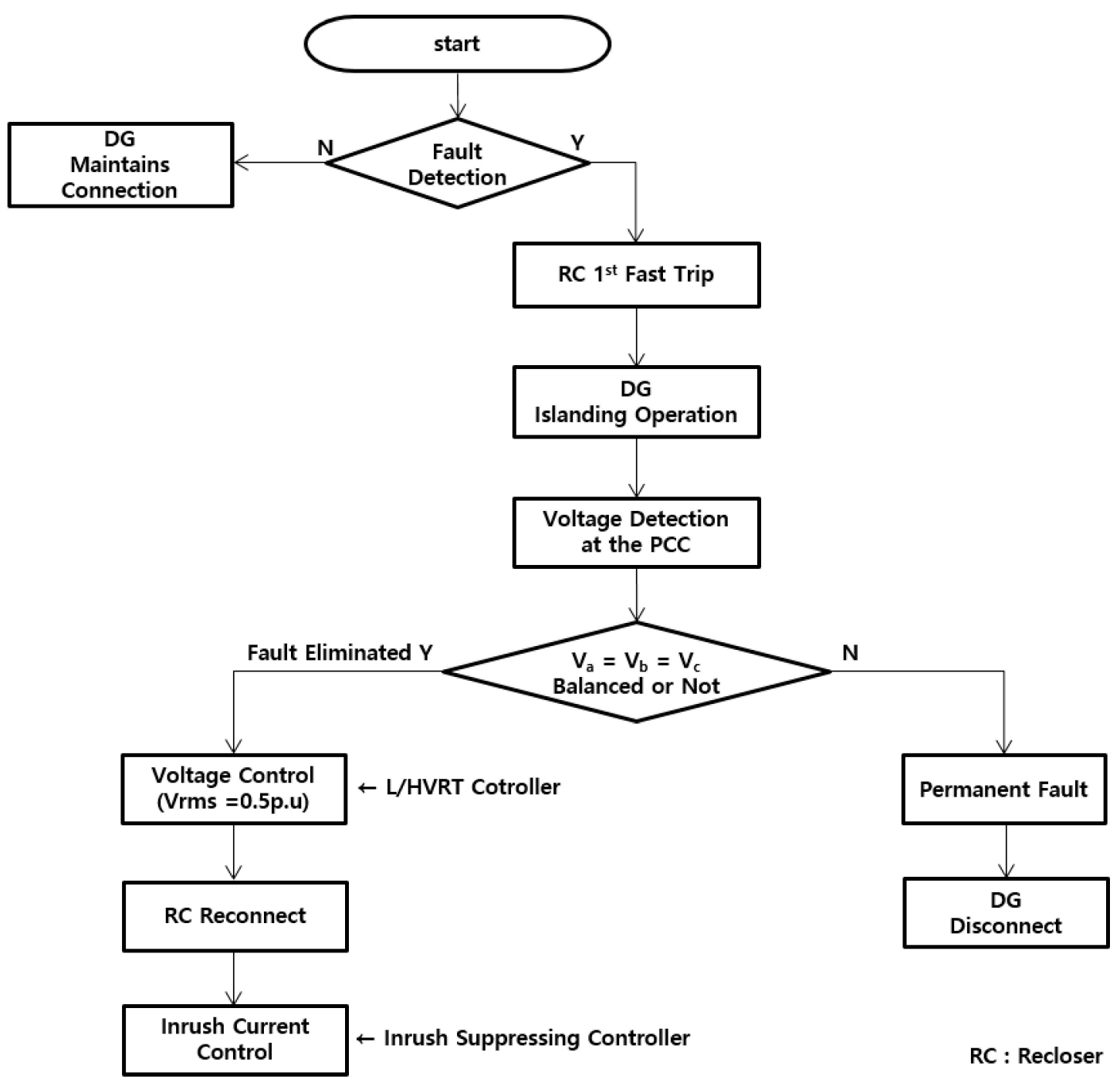

Figure 7. Proposed fault ride-through processing for a temporary fault. PCC: Point of Common Coupling.

\section{Simulation and Analysis}

In this section, we prove the proposed TFRT algorithm and control method by conducting a simulation and analyzing the results. Substation, PCS-based DG, load, and controllers were modeled through the PSCAD/EMTDC software package and the simulation was conducted according to the scenario set up to verify the continuous operation of DGs during temporary fault and restoration.

\subsection{Configuration of Distribution Systems with DGs and Loads}

The system configuration is shown in Figure 8, with the substation, distribution line, PCS-based DG, and loads. In addition, specific information on each model is summarized in Table 2. In the case of a renewable energy source, a model composed of a current controller is applied using the $\mathrm{d}$-q-axis current value for MPPT (Maximum Power Point Tracking). The load is considered as constant impedance and is distributed equally in consideration of the length of the distribution line. 


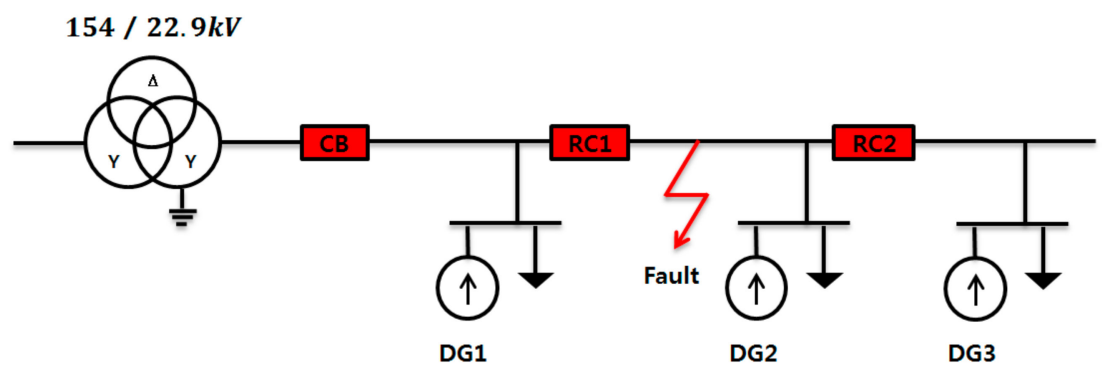

Figure 8. System model configuration.

Table 2. Specifications of the system model components.

\begin{tabular}{|c|c|c|}
\hline Index & Value & Remark \\
\hline \multicolumn{3}{|c|}{154 kV Grid Source } \\
\hline Positive Sequence $\% Z$ & $0.08+j 0.99$ & \multirow{2}{*}{$\begin{array}{c}100 \text { MVA } \\
\text { Based }\end{array}$} \\
\hline Zero Sequence $\% Z$ & $0.34+j 1.69$ & \\
\hline \multicolumn{3}{|c|}{ 3-Winding Transformer $(154 \mathrm{kV} / 22.9 \mathrm{kV} / 6.6 \mathrm{kV})$} \\
\hline Rated Power & 45/60 MVA & \multirow{5}{*}{$\begin{array}{c}45 \text { MVA } \\
\text { Based }\end{array}$} \\
\hline Positive Sequence $\% \mathrm{X}_{1-2}$ & $j 16.16$ & \\
\hline Positive Sequence $\% X_{2-3}$ & $j 6.69$ & \\
\hline Positive Sequence $\% \mathrm{X}_{3-1}$ & j 25.38 & \\
\hline Type & $Y-Y_{g}-\triangle$ & \\
\hline \multicolumn{3}{|c|}{ Distribution Generation (22.9 kV) } \\
\hline Rated Power of DG1 & \multicolumn{2}{|c|}{$1 \mathrm{MVA}(0.5 \mathrm{M} \times 2)$} \\
\hline Rated Power of DG2 & \multicolumn{2}{|c|}{$2 \mathrm{MVA}(0.5 \mathrm{M} \times 4)$} \\
\hline Rated Power of DG3 & \multicolumn{2}{|c|}{$1 \mathrm{MVA}(0.5 \mathrm{M} \times 2)$} \\
\hline Transformer Connection & \multicolumn{2}{|c|}{$Y_{g}-\triangle$} \\
\hline Positive Sequence $\% X$ & \multicolumn{2}{|c|}{ j 0.05} \\
\hline
\end{tabular}

\subsection{Configuration of Scenario}

In the temporary fault scenario, a single-line ground fault on a-phase occurs in $3.0 \mathrm{~s}$ and the recloser on the distribution line trips in $3.1 \mathrm{~s}$. In the case of a temporary fault, the fault lasts for $0.2 \mathrm{~s}$ and at $3.2 \mathrm{~s}$ the fault is eliminated. Therefore, the islanding operation period is divided into the one during $3.1 \mathrm{~s}$ to $3.2 \mathrm{~s}$ under fault condition and the other during $3.2 \mathrm{~s}$ to $3.6 \mathrm{~s}$ when the fault is eliminated. When a fault is cleared and DGs are ready to connect to the system, the recloser recloses in $3.6 \mathrm{~s}$. Figure 9 shows a temporary fault scenario. In this section, the TFRT method in the case of a temporary fault is proved but also, in order to analyze the voltage at the moment of a permanent fault of the control algorithm, we added one scenario for a permanent fault separately from the temporary fault. 


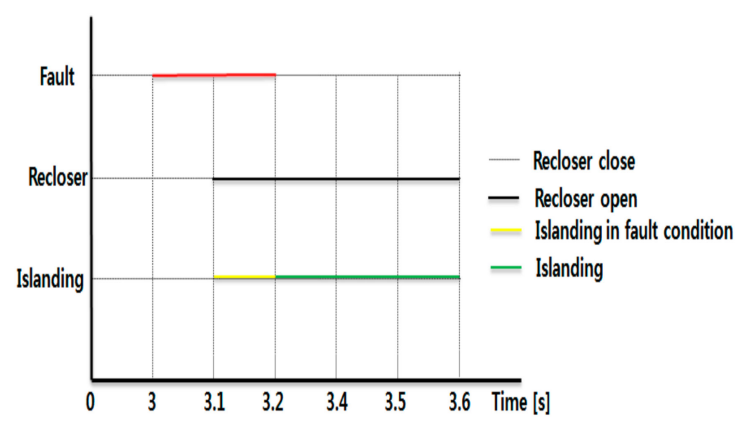

Figure 9. Simulation scenario for a temporary fault.

\subsection{Simulation Results and Analysis}

This section simulates the controller designed in the previous Section using the programming tool and analyzes the result. When a permanent fault occurs in a feeder with DG, the voltage waveforms at the PCC are shown in Figure 10. Therefore, DG perceives a permanent fault and disconnects.

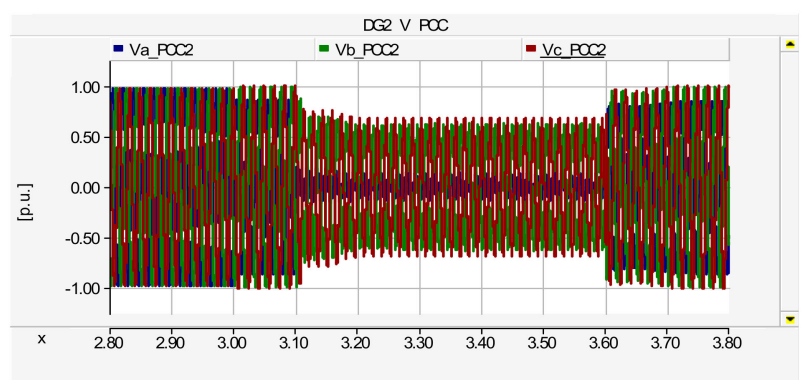

(a)

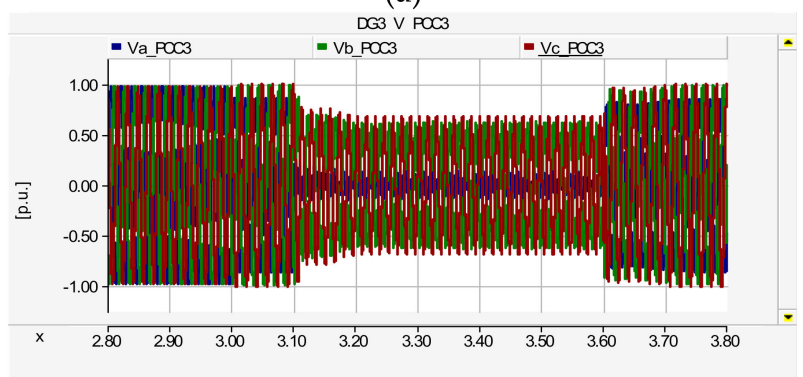

(b)

Figure 10. Phase Voltages at the PCC of DGs in the case of a permanent fault, (a) phase voltages at the PCC of DG2, (b) phase voltages at the PCC of DG3.

Firstly, the simulation waveforms for voltage and current when DG exceeds load are shown in Figure 10. Figure 10a shows the voltage of the PCC stage of DG2 and DG3. In Figure 11a, voltages are unbalanced between $3.1 \mathrm{~s}$ and $3.2 \mathrm{~s}$. Conversely, as the is fault eliminated after $3.2 \mathrm{~s}$, voltage is balanced. In this case, over-voltage occurred because the aggregated output of DGs is larger than the aggregated loads. However, when the proposed TFRT control method is applied, the voltage at the PCC was maintained at 0.5 p.u. In addition, over-voltage during reclosing of the recloser did not occur. Figure $11 \mathrm{~b}$ shows the output current of DG in islanding operation. After $3.2 \mathrm{~s}$, the output of DG1 upstream of the RC1 recloser does not change. The output currents in DG2 and DG3 remain constant after the fault is eliminated. However, inrush current occurred temporarily at $3.6 \mathrm{~s}$ when the RC1 recloser is reclosed. To solve this problem, when the proposed inrush suppressing control method was applied, the output currents of DGs increased and reduced the inrush current flowing from upstream. As a result, it is confirmed that the method can suppress the inrush current occurring during the reclosing period. 

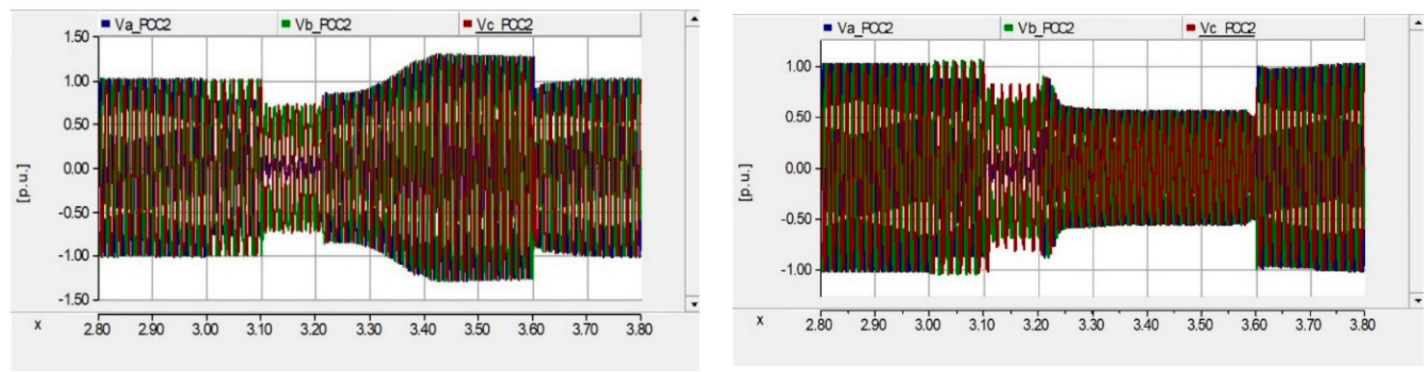

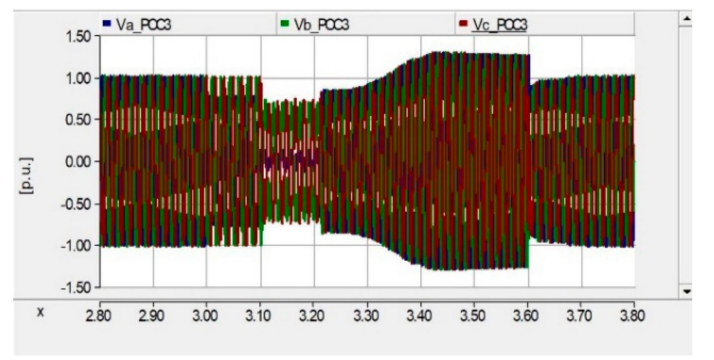

(When TFRT is not applied)

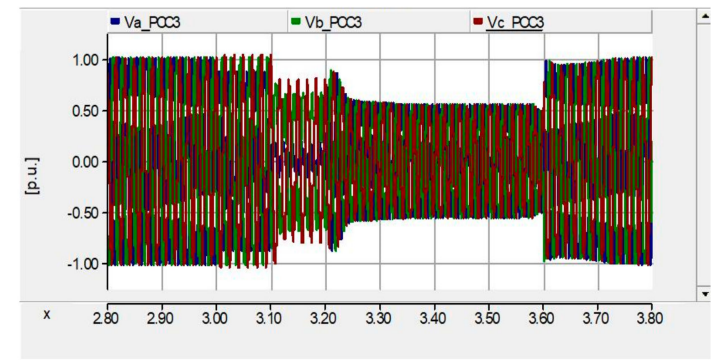

(When TFRT is applied)

(a) Phase voltages at PCC of DG2, 3
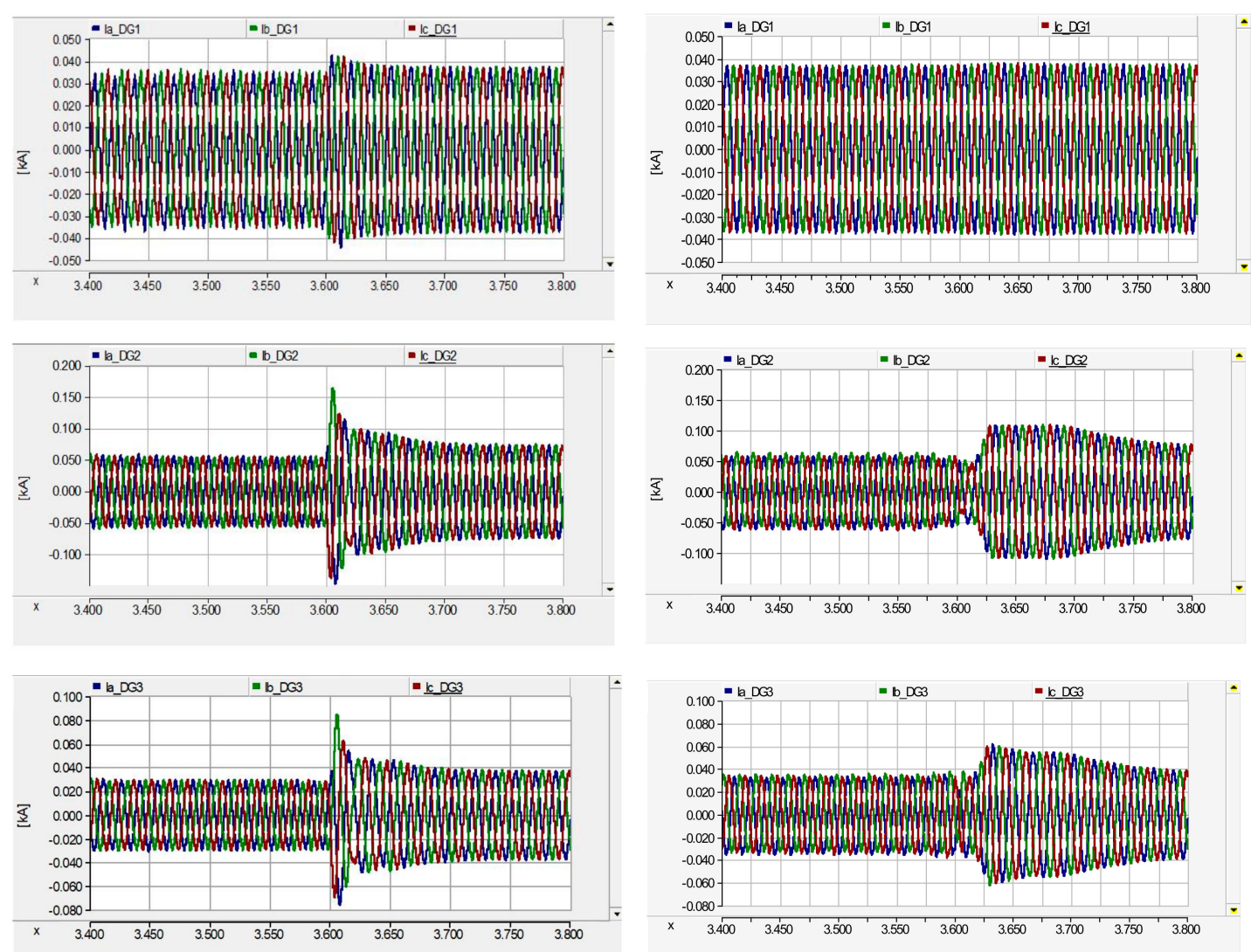

(When TFRT is not applied)

(When TFRT is applied)

(b) Phase currents from DG1, 2, 3

Figure 11. Comparison of the voltage and current with and without Temporary Fault Ride-Through (TFRT) control methods when the aggregated output of DGs is greater than the aggregated loads. 
Secondly, voltage and current waveforms are shown in Figure 12 when the aggregated loads are greater than the aggregated output of DGs. As above, after the fault is eliminated, control was implemented when the voltage is balanced. If control is not implemented, the voltage is less than 0.5 p.u. In this case, a fault is eliminated, but DG is disconnected as it is outside the permissible operating range of the VRT. However, when the voltage is controlled at 0.5 p.u. using the proposed voltage control algorithm, after the fault is eliminated, the voltage kept a constant within the permissible range so that DG2 and DG3 can continue to operate. In the case of current, the inrush current is reduced as shown in Figure $12 \mathrm{~b}$ using the proposed control method. Since the voltage is raised to maintain a voltage within the permissible range, the current was also higher than before the control.
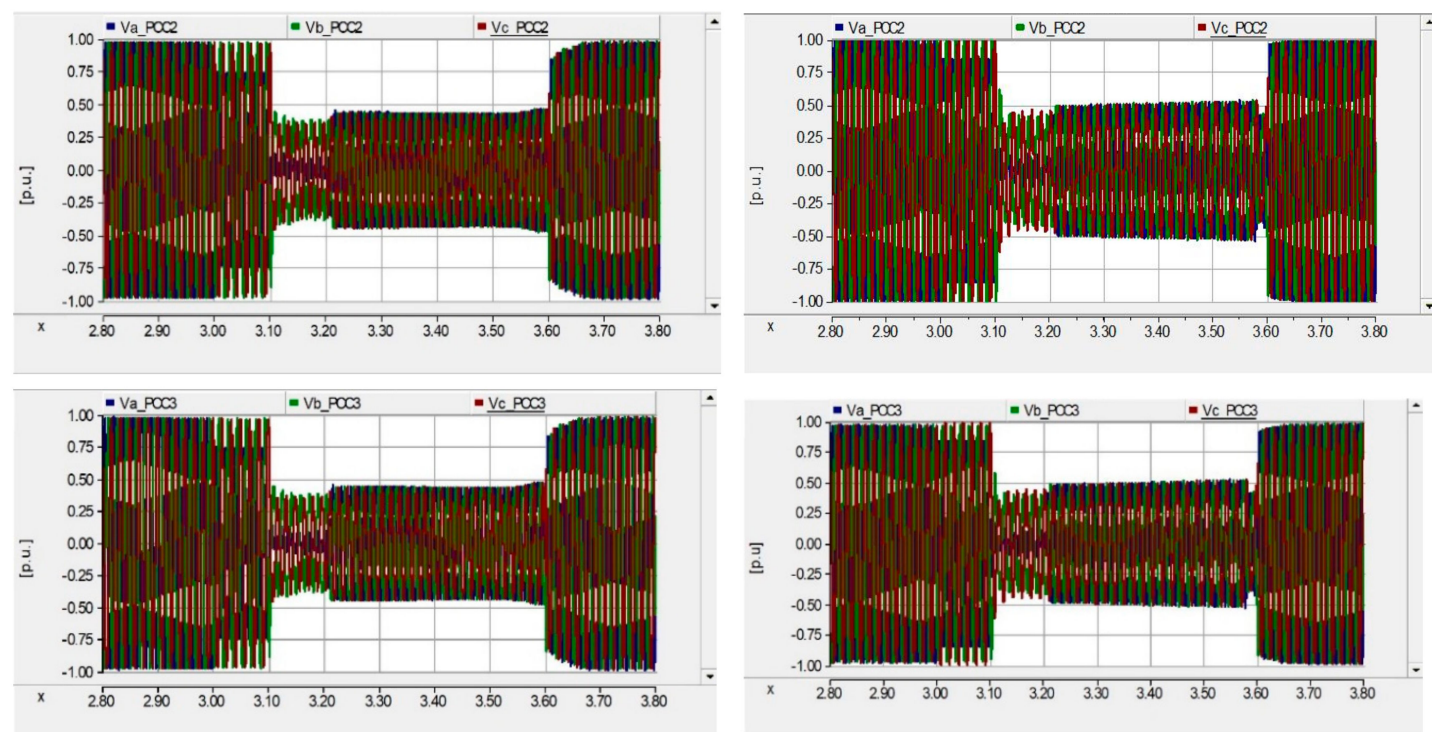

(When TFRT is not applied)

(When TFRT is applied)

(a) Phase voltage at PCC of DG2, 3
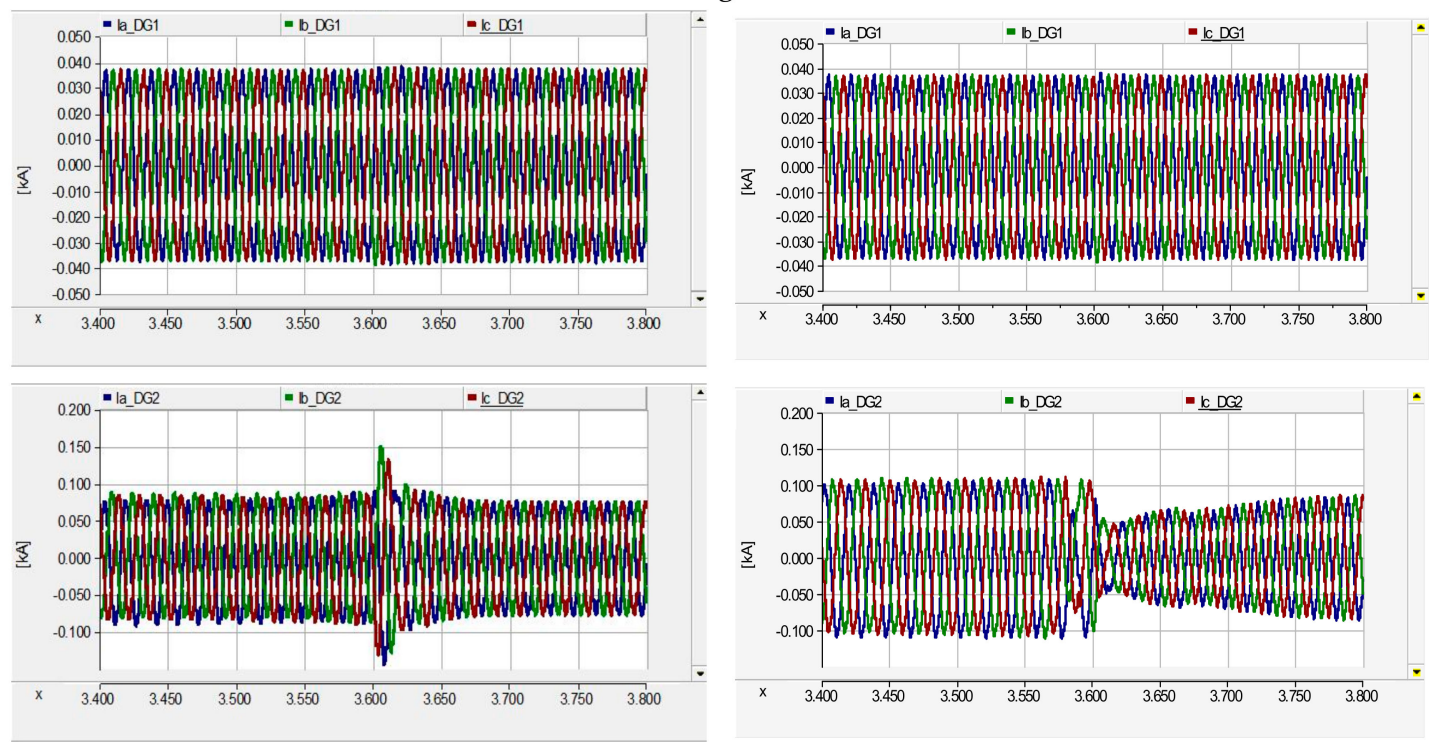

Figure 12. Cont. 


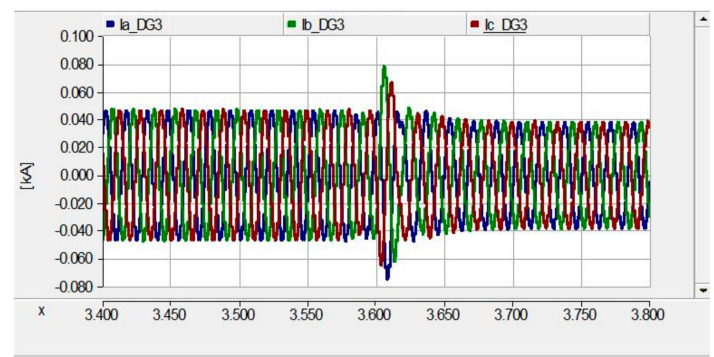

(When TFRT is not applied)

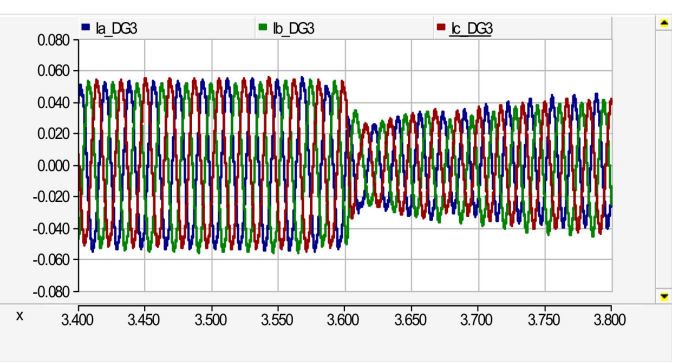

(When TFRT is applied)

(b) Phase current from DG1, 2, 3

Figure 12. Comparison of the voltage and current with and without TFRT control methods when the aggregated loads are greater than the aggregated output of DGs.

As seen from the above simulation results, if a fault is permanent or temporary can be decided according to whether the output voltage of DG is balanced or not. In the case of a permanent fault where the output of voltage of DG is not balanced, DG is disconnected. In the event of a temporary fault where the output voltage is balanced, it was proofed that DG can maintain the voltage within the VRT permissible voltage range by maintaining a constant voltage regardless of the amount generation and load. It was also proofed that the inrush current during the reclosing of the $\mathrm{CB}$ or recloser is lower than without TFRT. Simulation results show that the proposed TFRT method can work effectively for temporary faults in distribution systems.

\section{Conclusions}

The hosting capacity of power distribution systems for introducing DGs based on PCS such as renewable energy sources is increasing, and the number of rotor-based power plants is being reduced. This tendency makes the stability and power quality in power systems critical, especially in the event of a temporary fault in distribution systems. As a result, the large increase of DG deployment may lead to not only economic damage, but also system operation problems.

To solve these problems, the TFRT method is proposed. That is, at first, it is determined whether a fault in distribution systems is temporary or permanent. Then DG is disconnected for a permanent fault and continues to operate for a temporary fault by applying the proposed TFRT method. It was verified using the PSCAD/EMTDC software package that the TFRT method can control DGs to keep operating even if a temporary fault occurs. Also, it can control current and voltage to prevent damage due to over-/under-voltage and over-current occurred by the reclosing of the $\mathrm{CB}$ or recloser.TDC programming tool. proposed e as under/over- voltage occurred.

Finally, it is expected that the proposed TFRT method can improve the reliability and stability of distribution systems and is included in current grid code worldwide through further research.

Author Contributions: Validation, J.-S.O.; Investigation, S.-G.J. and D.-K.K.; Writing-original draft preparation, J.-H.L.; Writing-review and editing, J.-E.K.; All authors have read and agreed to the published version of the manuscript.

Funding: This research received no external funding.

Acknowledgments: This work was supported by the Korea Institute of Energy Technology Evaluation and Planning (KETEP) grant funded by the Korean government (MOTIE) (20181210301470, Development and Proof on the Commercialization of the Broker Service based on Small-scale Distributed Energy Resources).

Conflicts of Interest: The authors declare no conflict of interest.

\section{References}

1. Teodorescu, R.; Liserre, M.; Rodriguez, P. Grid Converters for Photovoltaic and Wind Power Systems; John Wiley \& Sons: New York, NY, USA, 2011. 
2. Global Trends in Renewable Energy Investment 2014; Bloomberg New Energy Finance: Washington, DC, USA, 2014.

3. Korea Electric Power Corporation. Guideline of Interconnection Technology of Distributed Generation in Distribution System; Korea Electric Power Corporation: Naju, Korea, 2015.

4. Zidan, A.; El-Saadany, E.F. Incorporating load variation and variable wind generation in service restoration plans for distribution systems. Energy 2013, 57, 682-691. [CrossRef]

5. McDermott, T.E.; Dugan, R.C. PQ, reliability and DG. IEEE Ind. Appl. Mag. 2003, 9, 17-23. [CrossRef]

6. Kamel, R.M.; Chaouachi, A.; Nagasaka, K. RETRACTED: Wind power smoothing using fuzzy logic pitch controller and energy capacitor system for improvement Micro-Grid performance in islanding mode. Energy 2010, 35, 2119-2129. [CrossRef]

7. Zidan, A.; Khairalla, M.; Abdrabou, A.M.; Khalifa, T.; Shaban, K.; Abdrabou, A.; El Shatshat, R.; Gaouda, A.M. Fault Detection, Isolation, and Service Restoration in Distribution Systems: State-of-the-Art and Future Trends. IEEE Trans. Smart Grid 2017, 8, 2170-2185. [CrossRef]

8. Wang, F.; Chen, C.; Li, C.; Cao, Y.; Li, Y.; Zhou, B.; Dong, X. A Multi-Stage Restoration Method for Medium-Voltage Distribution System with DGs. IEEE Trans. Smart Grid 2017, 8, 2627-2636. [CrossRef]

9. Arefifar, S.A.; Mohamed, Y.A.-R.I.; El-Fouly, T.H. Optimized Multiple Microgrid-Based Clustering of Active Distribution Systems Considering Communication and Control Requirements. IEEE Trans. Ind. Electron. 2014, 62, 711-723. [CrossRef]

10. Dewadasa, M.; Ghosh, A.; Ledwich, G.F. Islanded operation and system restoration with converter interfaced distributed generation. In Proceedings of the 2011 IEEE PES Innovative Smart Grid Technologies, Perth, WA, Australia, 13-16 November 2011; pp. 1-8.

11. Ghoddami, H.; Yazdani, A. A Mitigation Strategy for Temporary Overvoltages Caused by Grid-Connected Photovoltaic Systems. IEEE Trans. Energy Convers. 2014, 30, 413-420. [CrossRef]

12. Guo, F.; Wen, C.; Mao, J.; Song, Y.-D. Distributed Secondary Voltage and Frequency Restoration Control of Droop-Controlled Inverter-Based Microgrids. IEEE Trans. Ind. Electron. 2014, 62, 4355-4364. [CrossRef]

13. Lissandron, S.; Sgarbossa, R.; Santa, L.D. DeltaP—deltaQ Area Assessment of Temporary Unintentional Islanding with Pf and QV Droop Controlled PV Generators in Distribution Networks. In Proceedings of the IEEE Energy Conversion Congress and Exposition, Montreal, QC, Canada, 20-24 September 2015.

14. Dietmannsberger, M.; Wang, X.; Blaabjerg, F. Restoration of Low-Voltage Distribution Systems with Inverter-Interfaced DG Units. IEEE Trans. Ind. Appl. 2018, 54, 5377-5386. [CrossRef]

15. Gao, F.; Iravani, M. A Control Strategy for a Distributed Generation Unit in Grid-Connected and Autonomous Modes of Operation. IEEE Trans. Power Deliv. 2008, 23, 850-859.

16. Nguyen, C.P.; Flueck, A.J. Agent Based Restoration with Distributed Energy Storage Support in Smart Grids. IEEE Trans. Smart Grid 2012, 3, 1029-1038. [CrossRef]

17. Lo, Y.L.; Wang, C.H.; Lu, C.N. A Multi-Agent Based Service Restoration in Distribution Network with Distributed Generations. In Proceedings of the 2009 15th International Conference on Intelligent System Applications to Power Systems, Curitiba, Brazil, 8-12 November 2009; pp. 1-5.

18. Elmitwally, A.; Elsaid, M.; Elgamal, M.; Chen, Z. A Fuzzy-Multiagent Service Restoration Scheme for Distribution System with Distributed Generation. IEEE Trans. Sustain. Energy 2015, 6, 1-12. [CrossRef]

19. Sharma, A.; Srinivasan, D.; Trivedi, A. A Decentralized Multiagent System Approach for Service Restoration Using DG Islanding. IEEE Trans. Smart Grid 2015, 6, 2784-2793. [CrossRef]

20. McArthur, S.D.J.; Davidson, E.M.; Catterson, V.M.; Dimeas, A.L.; Hatziargyriou, N.D.; Ponci, F.; Funabashi, T. Multi-agent systems for power engineering applications-Part I: Concepts, approaches, and technical challenges. IEEE Trans. Power Syst. 2007, 22, 1743-1752. [CrossRef]

21. McArthur, S.D.J.; Davidson, E.M.; Catterson, V.M.; Dimeas, A.L.; Hatziargyriou, N.D.; Ponci, F.; Funabashi, T. Multi-agent systems for power engineering applications-Part II: Technologies, standards, and tools for building multi-agent systems. IEEE Trans. Power Syst. 2007, 22, 1753-1759. [CrossRef]

22. Shirmohammadi, D. Service restoration in distribution networks via network reconfiguration. IEEE Trans. Power Deliv. 1992, 7, 952-958. [CrossRef]

23. IEEE Standards Association. IEEE 1547 Standard for Interconnection and Interoperability of Distributed Resources with Assoiated Electric Power Systems Interface; IEEE Standards Coordinating Committee: Washington, DC, USA, 2018. 
24. International Electrotechnical Commission. IEC TS 62786 Distributed Energy Resources Connection with the Grid; International Electrotechnical Commission: Geneva, Switzerland, 2017.

25. CENELEC. EN 50549-1,2 Requirements for Generating Plants to be Connected in Parallel with Distribution Networks; CENELEC: Brussels, Belgium, 2019.

26. ENTSO-E AISBL. ENTSO-E Netwrk Code for Requirements for Grid Connection Applicable to all Generators; ENTSO-E: Brussels Belgium, 2013.

27. Bründlinger, R.; Schaupp, T.; Arnold, G.; Schäfer, N.; Graditi, G.; Adinolfi, G. Implentation of the European Network Code on Requirements for Generators on the European nation level. In Proceedings of the Solar Integration Workshop 2018: 8th International Workshop on Integration of Solar Power into Power Systems, Stockholm, Sweden, 16-17 October 2018.

28. Lopez, M.A.G.; De Vicuña, L.G.; Miret, J.; Castilla, M.; Guzmán, R. Control Strategy for Grid-Connected Three-Phase Inverters During Voltage Sags to Meet Grid Codes and to Maximize Power Delivery Capability. IEEE Trans. Power Electron. 2018, 33, 9360-9374. [CrossRef]

29. Zarei, S.F.; Mokhtari, H.; Ghasemi, M.A.; Blaabjerg, F. Reinforcing Fault Ride Through Capability of Grid Forming Voltage Source Converters Using an Enhanced Voltage Control Scheme. IEEE Trans. Power Deliv. 2019, 34, 1827-1842. [CrossRef]

30. Zidan, A.; El-Saadany, E.F. A Cooperative Multiagent Framework for Self-Healing Mechanisms in Distribution Systems. IEEE Trans. Smart Grid 2012, 3, 1525-1539. [CrossRef]

31. Ha, B.-N.; Lee, S.-W.; Shin, C.-H. Current practice of distribution automation technology and prospect. In Proceedings of the Summer Conference of Korean Institute of Electrical Engineers, Gangwon, Korea, 16-18 June 2008; pp. 313-314.

32. Oh, J.-H.; Yun, S.-Y.; Kim, J.-C.; Kim, E.-S. Particular characteristics associated with temporary and permanent fault on the multi-shot reclosing scheme. In Proceedings of the IEEE Power Engineering Society Summer Meeting, Seattle, WA, USA, 16-20 July 2003; pp. 421-424.

33. Liu, C.-C.; Lee, S.; Venkata, S. An expert system operational aid for restoration and loss reduction of distribution systems. IEEE Trans. Power Syst. 1988, 3, 619-626. [CrossRef]

34. International Electrotechnical Commission. IEC 61727 ed2.0 Photovoltaic(PV) Systems Characteristics of the Utility Interface; International Electrotechnical Commission: Geneva, The Netherlands, 2004.

35. VDE Association for Electrical, Electronic and Information Technologies. VDE-AR-N 4105:2011-08 Power Generation Systems Connected to the Low Voltage Distribution Network; VDE Association for Electrical, Electronic and Information Technologies: Frankfurt, Germany, 2011.

36. BDEW German Association of Energy and Water Industries. BDEW Generating Plants Connected to the Medium-Voltage Network; BDEW German Association of Energy and Water Industries: Berlin, Germany, 2008.

37. Japan Electric Association. Grid Interconnection Code (JEAC 9701-2012); Japan Electric Association: Chiyoda, Japan, 2012.

38. Barker, P. Overvoltage considerations in applying distributed resources on power systems. In Proceedings of the 2002 IEEE Power Engineering Society Summer Meeting, Chicago, IL, USA, 21-25 July 2002; Volume 1, pp. 109-114.

39. Shin, S.-S.; Oh, J.-S.; Jang, S.-H.; Chae, W.-K.; Park, J.; Kim, J.-E. A Fault Analysis on AC Microgrid with Distributed Generations. J. Electr. Eng. Technol. 2016, 11, 1600-1609. [CrossRef] 